\title{
VALUE FROM SHREDDER WASTE: ONGOING LIMITATIONS IN THE UK
}

\section{O.T. Forton ${ }^{a}$, M.K. Harder ${ }^{a^{*}}$ and N.R. Moles ${ }^{b}$}

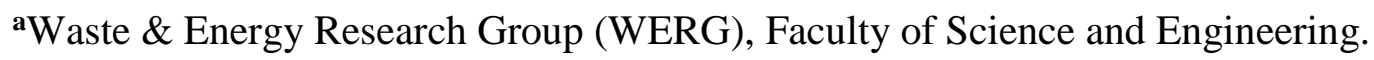

University of Brighton. BN2 4GJ, UK

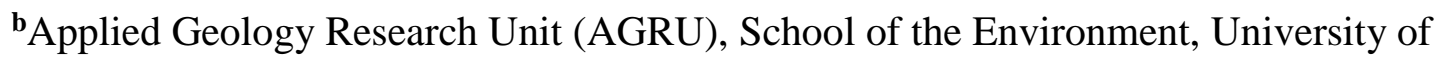
Brighton. BN2 4GJ, UK

*Corresponding author. Tel.: +44 1273 642539; fax: +44 1273642285.

E-mail address: m.k.harder@brighton.ac.uk (M.K. Harder). 


\begin{abstract}
Shredder residue is the residue from the shredding of end-of-life vehicles and white goods, after removal of the main metals. Approximately 850,000 tonnes of shredder waste is produced in the UK each year, and historically sent to landfill. Due to European legislation such as the End-of-Life Vehicle (ELV) Directive and the Landfill Directive there is pressure to minimize this waste through recycling and recovery.
\end{abstract}

In this paper primary data is presented showing that $40 \%$ of materials are potentially recoverable in the coarser fraction of UK automotive shredder residue $(>30 \mathrm{~mm})$. Barriers to such recycling are discussed in the context of several recent drivers, including this waste's possible reclassification as hazardous.

The lack of full and timely implementation of the ELV Directive in the UK has made it an ineffective driver, and it is now unlikely that its 2006 recycling targets will be met as intended.

Keywords: End-of-life vehicles, shredder residue, automotive shredder residue, white goods, Landfill Directive, ELV Directive, hazardous waste, pyrolysis, waste composition 


\section{Introduction}

In the UK, 430 million tonnes of wastes are produced per annum, 5 million of which is hazardous (DEFRA, 2004). This proportion is set to increase with the reclassification of several waste streams across the EU as hazardous waste under the harmonised European Waste Catalogue (EWC) and hazardous waste list (HWL).

In the European Union, legislative drivers such as the Packaging and Packaging Waste Directive (94/62/EC), Landfill Directive (99/31/EC) and the End-of-life Vehicle (ELV) Directive (2000/53/EC) are having a significant impact on the waste produced from various processes. Waste streams such as end-of-life vehicles (ELVs), waste from electrical and electronic equipment (WEEE), packaging waste, waste oils, sewage sludge, batteries and accumulators are amongst those particularly requiring proper management. In 1990, the European Union Environmental Council approved the EU Commission's Strategy for waste management in which these wastes were prioritized, with emphasis on prevention and recycling. Relevant legislation associated with the management of these wastes has been adopted at the European level, to be later transposed into the national legislation of member countries (Collins et al, 2002).

The main aim of this paper is to present current issues and drivers at play on ELV management in the UK, and to outline their actual effects on the ground. Data is presented to indicate the tonnages of potentially recoverable materials from ASR which is nonetheless still not recovered from it. 


\section{Traditional ELV management and shredding}

It is estimated that 30 million end-of-life vehicles arise annually worldwide with Europe accounting for about 14 million ELVs (European Commission, 2000b; Johnson and Wang, 2002) and the USA accounting for approximately 9-11 million ELVs per annum (Tonn et al, 2003). In the UK, an estimated 2 million ELVs are processed each year (ACORD, 2001). In Europe, the number of ELVs is projected to rise to 17 million by 2015, also increasing its proportion of general waste (Collins et al, 2002).

End-of-life vehicles have for decades been one of the most highly recycled consumer products, principally for the recovery of metals which account for about $75 \%$ by weight of an average automobile. The first stage of ELV management is at a dismantling centre where the automobiles are usually depolluted by removing components such as batteries and fluids. Components which have an obvious economic value are also salvaged at this stage. These components are then resold or recycled through the appropriately established outlets. The remaining bulk of the car is sent to a shredding facility for recovery of metals (mostly steel). Fig. 1 shows a basic schema of the shredding process. Processing operations are shown in bold.

\section{INSERT FIG. 1}

End-of-life vehicles are fed into hammer mills (fragmentisers) which size-reduce all of the components of the ELVs into pieces fist-sized or smaller. These are then separated using an array of processes such as air classification, magnetic and eddy current separation into three major material streams: ferrous scrap, non-ferrous scrap, 
and automotive shredder residue (ASR). Magnetic separation is used to recover iron and steel while the eddy current and heavy media separation plants are used to recover non-ferrous metals, together accounting for around $75 \%$ of an average car, typically 13 years old. The remaining $25 \%$ of an ELV is termed automotive shredder residue (ASR) and is generally disposed of as waste into landfill (ACORD 2001; Tonn et al, 2003). The recovered ferrous and non ferrous scrap will generally end up in blast or electric arc furnaces operating both in the UK and overseas for further processing in secondary metals industries.

Most shredders worldwide process ELVs alongside other consumer products including white goods, light iron and metallic manufacturing and construction waste (Ambrose et al, 2000; Singh et al, 2001). In such cases a more general term, shredder residue (SR), is used to describe the associated waste produced at the end of the shredding process. The UK currently has about 38 shredding facilities (Kollamthodi et al., 2003).

Throughout Europe, about 3 million tonnes of ASR is produced per annum (Johnson and Wang, 2002). In the UK, ELVs contribute about 450,000 tonnes of the 850,000 tonnes of shredder residue ending up in the landfills around the country, accounting for about $0.1 \%$ of total UK waste arisings (ACORD, 2001). In the USA, about 2.5-3 million tons of ASR are disposed of annually, accounting for $1.5 \%$ of the total municipal landfill waste (Tonn et al, 2003). These wastes from shredding facilities are a very specialised waste stream, with unique problems that should not be underestimated in the framework of sustainable resource utilisation and waste management. ASR and SR have become the subject of intense debates due to the 
increasing scarcity of landfill space and the potentially hazardous nature of some of their elements.

\section{Impacts of recent legislation}

\subsection{The impact of the ELV Directive on the ELV management chain}

The End-of-Life Vehicle (ELV) Directive (2000/53/EC) passed into European Law in October 2000 and aims to minimise the negative environmental impact of ELVs by progressively reducing the proportions of wastes from ELVs that are sent to landfills annually, by encouraging reuse, recycling and recovery through a variety of mechanisms.

It requires EU member states to set legislation to set up these mechanisms, and to meet recycling and recovery targets in 2006 and 2015 of $75 \%$ and $85 \%$, and of $85 \%$ and $95 \%$ respectively. For the UK this means that the amounts of ELV waste currently landfilled (25\%), will have to be reduced to $15 \%$ by 2006 and $5 \%$ by 2015 (European Commission, 2000b). The Directive also bans the use of certain hazardous substances, such as lead, cadmium, hexavalent chromium and mercury in certain applications in new automobiles.

Full implementation of the Directive is expected to include producer responsibility, design for recycling, and depollution prior to shredding. In the UK the new depollution issues have been addressed by the transposition into law of this particular aspect through the ELV Regulations 2003 and the ELV (Storage \& Treatment) 
[England \& Wales] Regulations 2003. It required Authorised Treatment Facilities (ATF) to be set up to ensure more stringent depollution is carried out. ATFs will also issue relevant Certificates of Destruction to regulate the de-registration of ELVs, which will help reduce the problem of abandoned vehicles in the UK.

Previous depollution commonly involved removal of batteries and tyres. The new regulations will ensure the certified removal of these as well as the majority of the vehicle fluids. Even the engines will be removed to minimize the contamination of engine oil to the SR waste produced subsequently at the shredding facility. However, the implementation of this part of the Directive has not been easy. Across the UK only 1,500 of the existing 3,500 dismantling centres have the appropriate waste management licences to operate under the new regulations (Kollamthodi et al, 2003). Others would require significant upgrading as a consequence of the Directive, and the cost of legitimate disposal in improved and appropriate ATFs will increase, leading to an increased number of abandoned ELVs (Smith et al, 2004). In the UK it is the local town council equivalent - Local Authority - which picks up the bill for abandoned vehicles, and these funds compete against those for schools and hospitals. The overall effect is thus potentially very significant to the local society generally, and would be very visible either as cuts in services provided, in the number of abandoned cars left undealt with, or as tax increases.

The European ELV Directive also makes clear statements about producer responsibility and design for recycling. However, these aspects have not yet been fully transposed into UK law. It might be thought that car manufacturers would be shouldering significant amounts of the costs of the impacts of these new legislations 
regarding ELVs. However, in the UK, lobbying has successfully allowed the issue to be clouded to the extent that neither car manufacturers or shredder companies have actually yet been obliged to invest in developing new depolluting or recycling/recovery facilities, and their development in the UK has thus been hindered. In March 2005 car manufacturers made responsible to collect their own marque of vehicles with the End-of-Life Vehicles (Producer Responsibility) Regulations 2005, but arrangements for the recovery of materials from them are still not specified.

Although initial collaborative work specifically on ASR had begun as early as 2000 (WERG 2002a and 2002b) funded by a Landfill Tax Credit Scheme set up by the government which allowed taxes on landfill to be used for $R \& D$, this Scheme was withdrawn for such purposes in 2003. Since the removal of such public funds collaborative progress has significantly slowed, with both industries unwilling to heavily invest in changes until such time as they are required to legally or financially in order to guarantee trade. Without the expected UK legislation, this has not happened. A knock-on effect has been that companies which invested in developing ASR recycling technology have not had sales as expected, and some have gone out of business.

\subsection{Hazardous waste reclassification-a new dilemma}

Separately to UK transposition of the EU ELV Directive, another major new source of legislative pressure has arisen in Europe with the reclassification of several components of ELVs and shredder waste as hazardous according to the European Commission Decision 2000/532/EC. The European Waste Catalogue (EWC) is a-non 
exhaustive list of waste types, in which wastes described as hazardous are labelled with an asterisk $(*)$ after the code (European Commission, 2000a). The catalogue was developed to provide a standard framework for comparison of waste statistics across all member states, and will have to be transposed into laws of member countries. Residues resulting from the shredding of non-depolluted ELVs which contain certain dangerous substances have been classed as hazardous wastes by the code $191003^{*}$, while similar residues resulting from ELVs which have been fully depolluted prior to shredding are classed as non hazardous wastes with the code 191004 (European Commission, 2000a).

In addition, some components of ELVs and shredder wastes including fluff light fraction and dust which contain dangerous substances (19 10 03*) and brake fluids $\left(16011^{*}\right)$ are now classed as hazardous waste. This reclassification will have farreaching consequences to the producers worldwide and will influence the way national legislation in other parts of the world develops. Implications will include liability issues and increased costs - very possibly resulting in unfavourable operational economics for current shredding businesses. In the UK SR waste has not yet been characterised for the purpose of legal classification. This means that all of the related industries are left hanging without clear legal advice as to whether the ELV waste they process need expensive new consideration as official hazardous waste, or not. They have not been willing to invest in any improved depollution technologies while waiting for legal direction from the government. It was in this context that the EU Landfill Directive came into effect on July 16, 2004, banning codisposal. Previously, shredder residues (SR) have traditionally been disposed of in landfills along with non hazardous wastes, where it is sometimes used as an overnight 
landfill cover material (Environment Agency, 2000). However, the new Landfill Directive required sites to be designated as suitable for either inert, non-hazardous or hazardous only. As ASR had not been classified formally, this created an immediate problem.

Many shredding companies reacted by stopping work. Even if they had been willing to pay higher costs to have the ASR landfilled as hazardous, some companies would have had difficulty finding a suitable landfill within a reasonable distance, as far fewer were now designated suitable.

After a series of negotiations, a compromise was eventually arrived at between the Environment Agency (the regulator) and the operators in the associated industry (Environment Agency, 2004). The producers of shredder wastes were given a 3 month window (August - October 2004) to develop an appropriate methodology for characterising the waste stream for disposal into the appropriate landfill sites. This time-window was later extended to February 2005. During this interim period the SR will continue to be disposed of as a non-hazardous waste. Subsequently, shredders will have to sufficiently demonstrate in their formal waste transfer notes that their waste resulting from depolluted ELVs is of a non hazardous nature in order to continue using established disposal options.

It is evident that the depollution and dismantling stage in the ELV management chain is the best point to put in place appropriate measures to ensure that potentially hazardous components are removed so that the downstream SR is not classified as hazardous. If this is to be successful, appropriate mechanisms must be put in place for 
financing such facilities together with increased cooperation between the dismantlers, vehicle manufacturers and producers.

\section{Material composition of coarse automotive shredder residues $(>30 \mathrm{~mm})$}

ASR is a heterogeneous mixture of plastics, glass, textiles, foam and metals and various hazardous metals (Bellmann and Khare, 2000; Ambrose et al, 2000). Its physical and chemical composition is highly variable depending on factors such as feedstock input into the shredder (which varies significantly from day to day and from site to site), location of the shredder, shredding equipment used, degree of wear in equipment, and nature of the downstream refinement processes (Lui et al, 1998; Ambrose et al, 2000).

The Waste and Energy Research Group (WERG) of the University of Brighton has been carrying out work to determine the potentially recyclable tonnages in ASR since 2000. This involved the specific collection of samples using only ELVs as a feed into shredder facilities, which was no small task, as shredders generally process them with other materials. Various analyses and developments for this material were carried out (WERG 2002a, 2002b). A summary of the types of material types in coarse fractions typical of ASR in the UK is presented in Fig. 2. This fraction, >30mm, represents about $50 \%$ of the total ASR stream.

\section{INSERT FIG.2}


Fig. 2 indicates that a significant proportion of material types including plastics, polyurethane foam, textiles, rubber and assorted metals and copper wire can potentially be recovered from coarse ASR fractions - typically $40 \%$ of it. All these material types could theoretically find markets, albeit low-value and not financially competitive ones, provided the appropriate technologies and mechanisms for recycling are put in place.

\section{Obtaining value from shredder waste materials}

Despite the potential for recovering materials from shredder wastes in large quantities for identified markets, a number of barriers exist. These barriers are legislative, technical and economical.

Some of the technologies that have been used or can potentially be used to recover material types, hence value, from SR include heavy media separation, froth flotation, jigging, cryogenic grinding, use of magnets, air knives and vibrating tables (Jody et al, 1994; Buchan and Yarar, 1995; de Jong and Dalmijn, 1997; Scheirs, 1998; Trouve et al, 1998; Day et al, 1999; Brunner et al, 2000; Fraunholcz et al, 2000; Singh et al, 2001; Shen et al, 2002; Rubio et al, 2002). In Europe two companies were marketing integrated technologies involving an array of these processes to recover individual components from SR for sale in identified markets. These technologies have not yet been adopted in the UK, largely due to the stalemate in determining legal financial liability for ELV recovery processes and the delay in implementing the ELV Directive. In 2004, one of these companies closed down due to lack of business. 
Plastics constitute a significant proportion of ASR, but would have to be separated into individual types, or groups of types, for reuse in specific applications. The application of wet separation techniques, though a possibility, is not very efficient when separating even a modest mixture of plastics containing different fillers, pigments and reinforcing agents, since these modify the densities of the polymers, thereby affecting the way they separate (Schiers, 1988). For SR, containing a great mixture of plastics, the separation of the plastics into various types poses a major challenge.

Generally, markets and prices are controlled by the extent to which the recovered materials can meet relevant specifications for reuse (Henstock, 1998). Recyclates are still unfavourable relative to products made from virgin materials. In addition, identifying a stable market that can manage a continuous supply of such recyclates is difficult. For recycled plastics, however, some progress is being made in the UK with the assistance of a new government quango, WRAP (Waste Resources Action Programme). They have elicited the cooperation of CARE (Consortium for Automotive Recycling) to develop and validate generic specifications for engineering quality plastics containing recyclate, for use in the automotive industry (CARE, 2003). Recycled bound PU foam also shows promise for recycling as it is a more effective sound deafening material than continuous foam made from virgin material because it is made up of materials with varying densities and thus more disrupting acoustic phases (Blair, 1998; Brunner et al., 2000). 
For glass, there does not currently appear to be any process that would be able to substantially recover glass other than early removal before vehicle shredding. It is largely found in the fine trommel fraction but also occurs distributed throughout the coarse fractions. On the other hand, ASR contains small metal pieces that are missed in the early process of metal removal, and they are easy to remove by sampling using a further stage of magnets and eddy-current systems - a practice that is quickly catching on.

Shredder fines constitute approximately $50 \%$ of ASR, and are $<30 \mathrm{~mm}$. They are usually produced in a separate stream to those larger waste pieces discussed above, and include plastics, fibres and rubbers. This fraction also tends to have contamination from oil and other fluids. It would be inherently difficult to mechanically separate fines, but they can be used for energy recovery using a number of processes including pyrolysis, gasification and incineration. They can be used in cement kilns as an energy source in some countries. Pera et al. (2004) have shown that they can also be used in a number of building materials, either by transforming them into aggregates after thermal and chemical treatment or by using them directly in concrete with other types of cement. They are iron-rich and contain glass, sand and other filler materials, which are basic ingredients for building materials such as cement and aggregates. Work has also shown that significant amounts of metals can be recovered from fines by pyrolysing it, producing very significant amounts of gases which can potentially be combusted for electricity generation or condensed for fuel production (WERG 2003).

However, the fines fraction also contains lead metal, which is often considered an unwanted contaminant that can restrict further use. During the shredding process, 
various heavy metals end up in the SR. These contaminants, including lead, can potentially pose a serious limitation to the reuse of SR, because they are classified as hazardous. The variation seen in the levels of these contaminants present in ASR is still poorly understood, and the subject of ongoing studies (WERG 2005). Understanding the source of the contaminants and how to minimise them is essential to enable ASR to yield future marketable products, especially for the fine fraction.

In order to overcome the barriers to SR recycling, its material properties, including composition and contaminant levels, have to be determined and clearly understood. The quality specifications of the potential new markets have to be developed, and processes for resource recovery have to be developed in relation to the quality specifications of the identified markets. This requires the involvement of many key stakeholders in industry.

\section{Conclusion}

Primary data has been presented which shows that approximately $40 \%$ of coarser ASR (i.e. $20 \%$ of total ASR or $5 \%$ of an ELV) has potential for recovery using mechanical separation. Although some companies advertise processes which carry out separation of ASR into material types, they have not been taken up in the UK, where the legal obligation of producer responsibility for current ELVs has not yet been fully implemented, hindering investment.

Significant efforts will have to be made by the major stakeholders to achieve the targets of the ELV Directive (2000/EC/53) of $95 \%$ recycling and recovery by 2015 . 
At this time it is more likely that the 2006 targets will not be met in the UK, or even fully implemented as originally intended by that time. In the meantime, some companies which invested in separation technologies for ASR have closed down.

The ability to achieve the ELV Directive targets will now depend on a range of factors besides its implementation, including the indirect impact of other directives such as WEEE Directive (2000/96/EC), Landfill Directive (99/31/EC), and Hazardous Waste Directive (91/689/EEC). 


\section{References}

Automotive Consortium on Recycling and Disposal (ACORD). Annual Report 2001. London, UK 2001.

Ambrose, C.A. End-of-life (ELV) vehicle waste arising, disposal and legislation. Wastes Management. Northampton, UK, 2000; 44-46.

Ambrose, C. A., Singh, M. M. and Harder, M. K. The material composition of shredder waste in the UK. Institute of Waste Management Scientific \& Technical Review 2000:27-35.

Bellman, K. and Khare, A. Economic issues in recycling end-of-life vehicles. Technovation 2000; 20:677-690.

Blair, G.R. Recovery and Reuse of Automotive Shredder Residue Flexible Polyurethane Foam. ARC'98. Building the technology bridge to plastic recycling. 1998: 43-53.

Brunner, M., Mark, F. E. and Kamprath, A. Composition of old car seat foams. European Isocyanate Producers Association (ISOPA) and The Associations of Manufacturers of Moulded Polyurethane Parts for the Automotive Industry (EUROMOULDERS). Rapperswill, Switzerland, 2000. 
Buchan, R. and Yarar, B. Recovering of Plastics for Recycling by Mineral Processing Techniques. Journal of Metals.1995; 47(2):52-55.

Consortium for Automotive Vehicle Recycling (CARE). Prove Recycling works. Project summary. Plastics reprocessing and validation exercise. June 2003. Proverecycling.org/downloads/Projectsummary.pdf. [Accessed November 14 2004].

Collins, C., Fanning, A., Crowe, M. and Meaney, B. End of life vehicles in Ireland. A Sectoral Report. EPA. Ireland, 2002.

Day, M., Shen, Z. and Cooney, J. D. Pyrolysis of auto shredder residues: experiments with a laboratory screw kiln reactor. Journal of Analytical and Applied Pyrolysis 1999; 51(1-2):181 - 200.

de Jong, T. P. R. and Dalmijn, W. L. Improving jigging results on non-ferrous car scrap by application of an intermediate layer. International Journal of Mineral Processing 1997; 49:59-72.

Department for Environment, Food and Rural Affairs (DEFRA). e-Digest of Environmental Statistics. Key Facts about: Waste and Recycling. 2004. defra.gov.uk/environment/statistics/waste/kf/wrkf02.htm [Accessed November 14 2004.]

Environment Agency. Review and guidance on the use of landfill cover materials. Bristol. UK. 2000. From environment-agency.gov.uk/commondata/105385/ 
landfill_cover_876943.pdf. [Accessed November 28 2004.]

Environment Agency. Environment Agency Statement on Shredder Residues July 2004. From environment-agency.gov.uk/commondata/105385/149a._statement _831903.pdf. [Accessed November 14 2004.]

European Commission. Commission Decision of 3 May 2000 replacing Decision 94/3/EC establishing a list of wastes pursuant to Article 1(a) of Council Directive 75/442/EEC on waste and Council Decision 94/904/EC establishing a list of hazardous waste pursuant to Article 1(4) of Council Directive 91/689/EEC on hazardous waste. OJ L 226, 6.9.2000, p. 3; 2000a.

European Commission. Directive 2000/53/EC of the European Parliament and of the Council of 18 September 2000 on end-of-life vehicles. OJ of the EC. 2000b.

Fraunholcz, N., Schokker, E. A., Rem, P. C. and Dalmijn, W. L. A novel approach to the mechanical processing of ASR. In Stewart Jr., D. L., Daley, J. C., and Stephens, R.L.(eds). Proceedings of the 4th International Symposium on Recycling of Metals and Engineering materials.2000; 1303 - 1314.

Henstock, M. E. The impact of Materials Substitution on the Recyclability of Automobiles. Resources, Conservation Recycling 1988; 2:69-85. 
Jody, B. J. and Daniels, E. J. Automobile Shredder Residue: Treatment Options. Hazardous Waste \& Hazardous Materials 1991; 8(3):219 - 230.

Jody, B. J., Daniels, E. J., Bonsignore, P. V., and Brockmeir, N. F. Recovering Recyclable Materials from Shredder Residue. Journal of Metals 1994; 46(2):40 43.

Johnson, M. R. and Wang, M.H. Evaluation policies and automotive recovery options according to the European Union Directive on end-of-life vehicles (ELV). Proc. of the Inst. of Mech. Eng. 216 Part D: Automotive Engineering 2002; 216: 723 - 735.

Kollamthodi, S., Hird, A., Elghali, L., Johnstone,K., Wayman, M. and McColl, V. Data required to monitor compliance with the End of Life Vehicles Directive. Project Report PR SE/483/02 prepared for DEFRA by TRL Ltd. UK. 2003.

Lui, S. X., Winslow, G.R., Yester, S. Gromek, G. P., Crouch, A. and Sendijarevic, V. Shredding Late Model Chrysler Vehicles, ASR Sample Collection and Characterisation of ASR. SAE Spec. Pub. 1998; 1342: 217 - 230.

Pera, J., Ambroise, J. and Chabannet, M. Valorisation of automotive shredder residue in building materials. Cement and Concrete Research 2004; 34(4):557-562.

Rubio, J., Souza, M. L. and Smith, R. W. Overview of floatation as a wastewater treatment technique. Minerals Engineering 2002; 15(3): 139 - 155. 
Scheirs, J. Polymer Recycling. Science, Technology and Applications. John Wiley \& Sons. Chichester, UK. 1998.

Shen, H., Forssberg, E. and Pugh, R. J. Selective floatation of plastics by chemical conditioning with methyl cellulose. Resources, Conservation Recycling 2002; 35(4):229 - 241.

Singh, M. M., Williams, K. S., Hooper, R. and Harder, M. K. Proving the principlerecovery of plastics from shredded ELVs. Institute of Mechanical Engineers 6th International Conference on Engineering for Profit from Waste. 13 - 14 Nov. London, UK. 2001;181-189.

Smith, M., Jocobson, J. and Webb, B. Abandoned vehicles in England: Impact of the End of Life Directive and new initiatives, on Likely Future Trends. Resources, Conservation Recycling 2004; 41(3):177-189.

Tonn, B. E., Schexnayder, S. M., Peretz, J. H., Das, S. and Waidley, G. An assessment of waste issues associated with the production of new, lightweight, fuel-efficient vehicles. Journal of Cleaner Production 2003; 11: 753-765.

Trouve, G., Kauffmann, A. and Delfose, L. Comparative thermodynamic and experimental study of some heavy metal behavior during automotive shredder residues incineration. Waste Management 1998; 8(5):301-307. 
Waste \& Energy Research Group (WERG). Polymer Processing B: Towards Processing Polymers from ASR Polymer Processing. A report by the Waste and Energy Research Group, University of Brighton, commissioned by Brighton Environmental Body Ltd for the Consortium of Automotive Vehicle Recycling. 2002a.

Waste \& Energy Research Group (WERG). Pyrolysation of Shredder Residue (fine). A report by the Waste \& Energy Research Group, University of Brighton, commissioned by Brighton Environmental Body Ltd for the Consortium of Automotive Vehicle Recycling. 2002b.

Waste \& Energy Research Group (WERG). Improving Lead Levels in ASR. A report by the Waste and Energy Research Group, University of Brighton, commissioned by Brighton Environmental Body Ltd for the Consortium of Automotive Vehicle Recycling. 2005. 
Fig. 1 Schema of processes at a typical UK shredding facility (main processes are shown in bold)

Fig. 2. Proportions of individual material types that can potentially be recovered mechanically from ASR produced from a typical shredding plant - considering only the coarse and oversize fraction (Section 4).

Resources, Conservation and Recycling, O.T. Forton, M.K. Harder and N.R. Moles

Captions for Figures 1,2. 


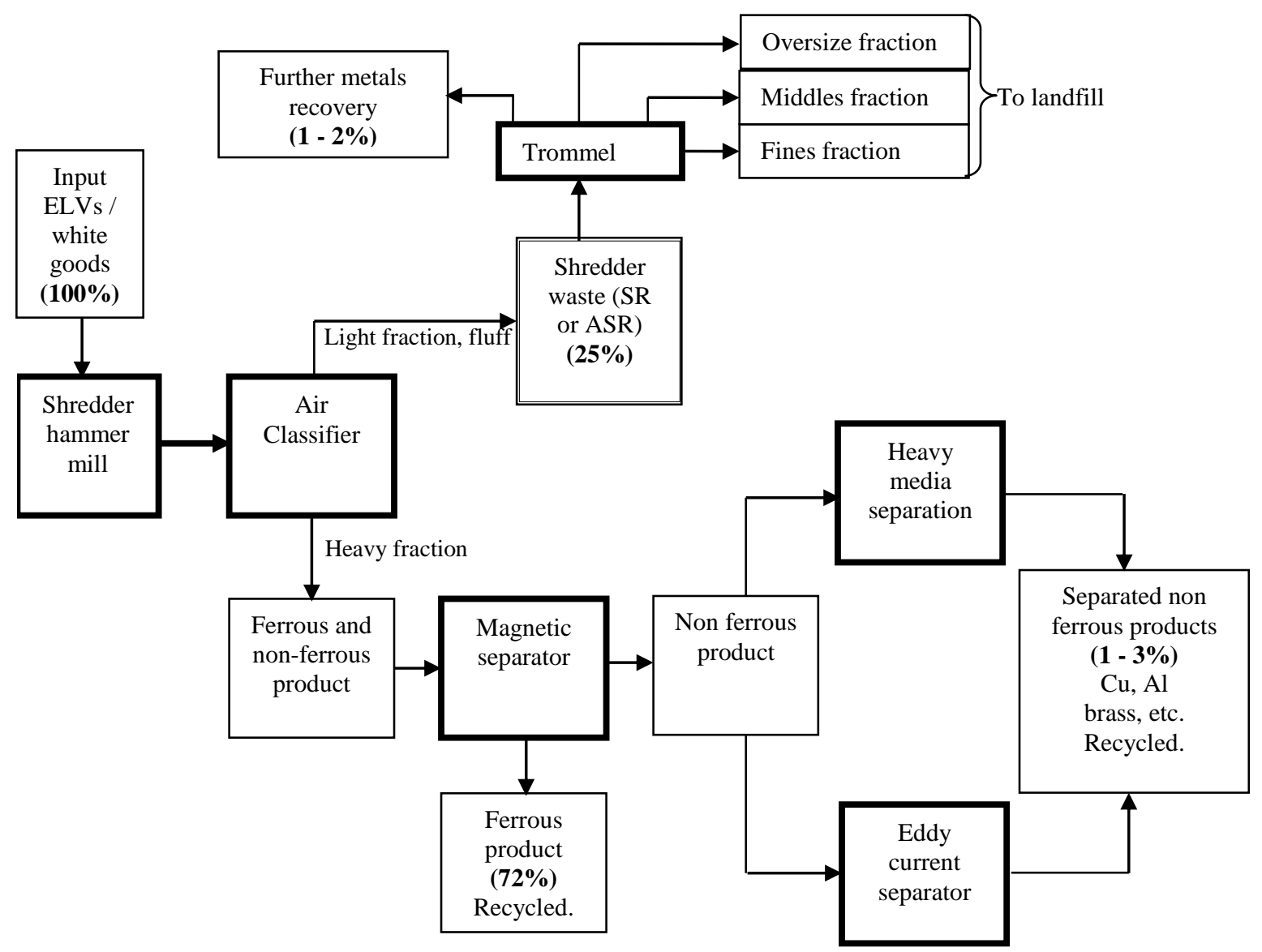

Resources, Conservation and Recycling, O.T. Forton, M.K. Harder and N.R. Moles

Fig. 1, Orientation: Portrait 


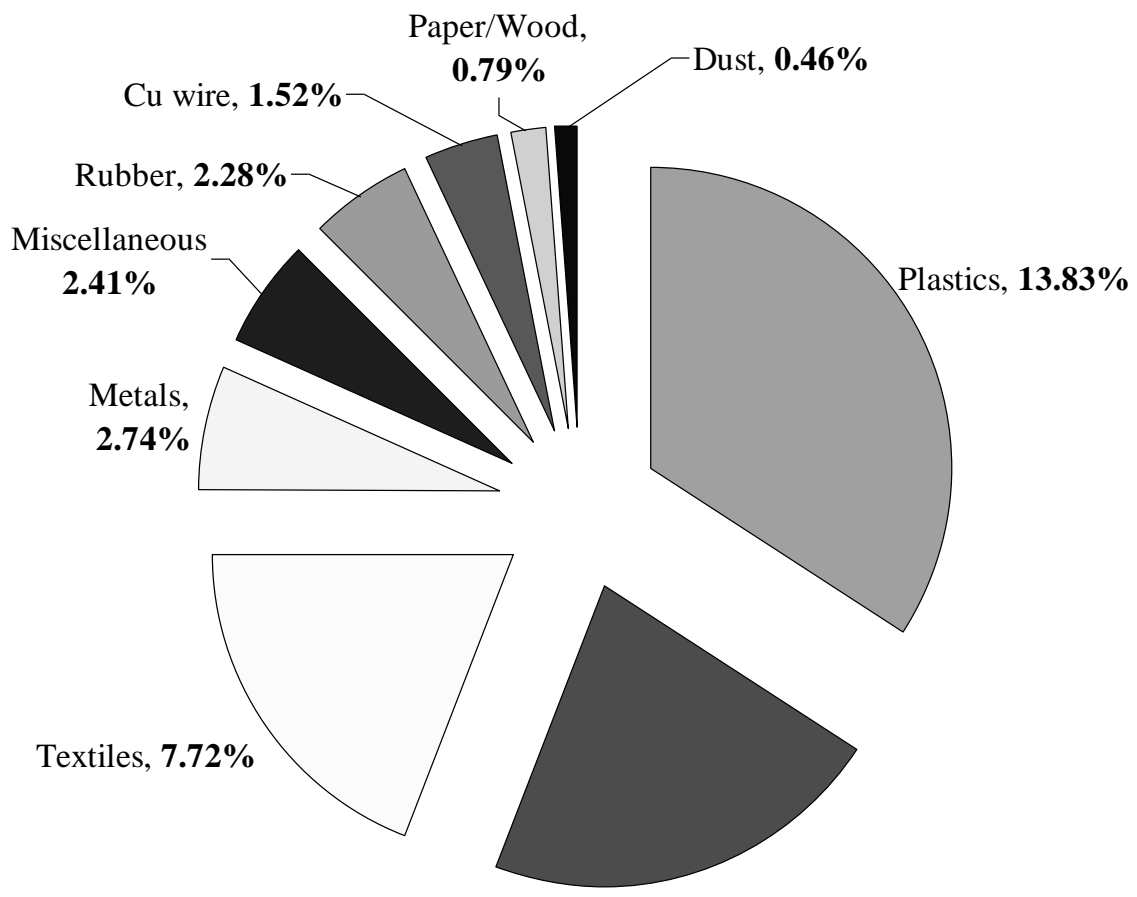

Foam, 8.89\%

Resources, Conservation and Recycling, O.T. Forton, M.K. Harder and N.R. Moles

Fig. 2, Orientation: Portrait 